\title{
Menisküs skafoldları
}

\author{
Meniscus scaffolds
}

\author{
Tahsin Beyzadeoğlu¹, Gökhan Meriç² \\ ${ }^{1}$ Haliç Üniversitesi Sağlık Bilimleri Yüksekokulu ve Beyzadeoğlu Kliniği, Ortopedi ve Travmatoloji Bölümü, İstanbul \\ ${ }^{2}$ Yeditepe Üniversitesi Hastanesi, Ortopedi ve Travmatoloji Bölümü, İstanbul
}

\begin{abstract}
Menisküsün geniş yırtıkları ve kronik hasarlanmaları sonrasında menisküsün tamiri her zaman mümkün olamamaktadır. Menisküs tamiri yapılan hastaların anatomik tamir yapılsa bile \%25'inden fazlasında başarısızlık görülmektedir. Menisküsün özellikle avasküler bölümünde olan geniş yırtıklarında menisküs tamiri mümkün olmamakta ve bu durumlarda menisküs çıkarılmaktadır. Menisküs yırtılması ve çıkartılması sonrası gelişebilen diz osteoartiriti ile sonuçlanabilen etkilerden korumak amacıyla, menisküs dokusu yerine geçecek meniskal skafold fikri ortaya atılmıştır. Menisküs skafoldları ile, menisküsün anatomik ve fibrokartilajinöz özellikleri taklit edilerek, menisektomi sonrası oluşabilen dejeneratif değişikliklerin gecikmesi veya önlenmesi amaçlanır. Kollajen ve poliüretan yapıda olmak üzere iki farklı menisküs skafoldu bulunmaktadır. Yapılan çalışmalarda, meniskal skafold uygulamalarını takiben hastaların fonksiyonel sonuçlarında anlamlı artış olduğu bildirilmektedir. Ancak, meniskal ekstrüzyon, rezorpsiyon gibi sorunlara bağlı olarak, meniskal skafoldların başarısızık oranı $\% 17,3$ ile \%46,7 arasında değişmektedir. Menisküs skafoldunu hücresel olarak aktifleştirmek ve normal menisküse benzer bir matriks elde etmek amacıyla, trombositten zengin plazma ve mezenşimal kök hücre emdirilmiş skafoldlar üzerine çalışmalar yapılmaktadır.
\end{abstract}

Anahtar sözcükler: menisküs; menisküs yırtığı; skafold; menisküs tamiri
Meniscus repair is not always possible after chronic damage and extensive rupture of the meniscus. Even if anatomical repair of meniscus is performed, more than $25 \%$ failure is seen in patients after meniscal repair. Large ruptures of the meniscus, especially in avascular part, are not able to repair, and these parts of the meniscus are resected. A meniscus scaffold idea was introduced to replace the meniscus tissue in order to protect the knee against the effects of osteoarthritis that may develop after meniscal rupture and resection. The aim of the meniscus scaffold treatment is to delay or prevent degenerative changes that may occur after meniscectomy by mimicking the anatomical and fibrocartilaginous properties of the meniscus. There are two different meniscus scaffold types: in collagen and polyurethane structure. It has been reported that there is a significant increase in the functional outcomes of patients following meniscal scaffold applications. However, the failure rate of meniscal scaffolds varies between $17.3 \%$ and $46.7 \%$ depending on problems such as meniscal extrusion and resorption. Platelet-rich plasma and mesenchymal stem cell-added scaffolds are being studied to activate the meniscus scaffold cellularity, and to obtain a normal meniscus-like matrix.

Key words: meniscus; meniscus tear; scaffold; meniscus repair

aktarımının sağlanmasına yardımcı olur. GAG'lar, menisküsün viskoelastik yapısının sağlanmasında, kompresif dayanıklılıkta ve doku hidrasyonunda önemli rol alır. ${ }^{[2]}$ Menisküsün bu yapısal özellikleri; kıkırdak yüzeyi üzerinde yük dağılımının sağlanması, aksiyel yüklenme esnasında yüklenme stres yüklerinin eklem kıkırdağı üzerinde dağılması, eklemin fleksiyon ve ekstansiyon sırasında stabilizasyonu ve eklem yağlaması gibi birçok görevi yapmasına olanak sağlar. ${ }^{[3]}$

- İletişim adresi: Prof. Dr. Tahsin Beyzadeoğlu, Haliç Üniversitesi Sağlık Bilimleri Yüksekokulu ve Beyzadeoğlu Kliniği, Ortopedi ve Travmatoloji, İstanbul Tel: 0216 - 3605060 e-posta: tbeyzade@superonline.com

- Geliș tarihi: 1 Mart $2018 \quad$ Kabul tarihi: 1 Mart 2018 
Menisküsün geniş yırtıkları ve kronik hasarlanmaları sonrasında menisküsün tamiri her zaman mümkün değildir ve tamir edilse dahi sonuçları her zaman yüz güldürücü olmamaktadır. ${ }^{[4]}$ Menisküs tamiri yapılan hastaların, anatomik tamir yapılsa bile \%25'inden fazlasında başarısızlık görülmektedir. ${ }^{[3]}$ Menisküs tamiri, menisküsün özellikle avasküler bölümünde mümkün olmamakta ve bu durumlarda menisküs çıkarılmaktadır. ${ }^{[4]}$ Menisküsün cerrahi olarak çıkartılması, kompartmanda eklem yüzeyinde yük stresinin artmasına, diz fonksiyonlarında gerilemeye ve eklemde dejenerasyona gidişe neden olabilir. ${ }^{[5]}$

Menisküs yırtılması ve çıkartılması sonrası, menisküs defektleri meydana gelir ve buna bağlı diz osteoartriti gelişebilir. Bu dejeneratif bozukluk ile sonuçlanabilen etkilerden korumak amacıyla, menisküs dokusu yerine geçecek meniscal scaffold (çatı implantı) fikri 1990’lı yıllarda ortaya atılmıştır. Menisküs skafoldları ile, menisküsün 3-boyutlu yapısını ve fibrokartilajinöz özelliği taklit edilerek, menisektomi sonrası oluşabilen dejeneratif değişikliklerin gecikmesi veya önlenmesi amaçlanır. Piyasada, menisküs skafoldu olarak kullanılabilen iki ürün bulunmaktadır. Bunlar;

- CMI (collagen meniscus implant)-Menaflex ${ }^{\circledR}$ (Ivy Sports Medicine GmbH, Grafelfing, Almanya ve ReGen Biologics, Inc., Franklin, Lakes, NJ) skafold kollajen yapısındadır. Skafoldun \%97'si Tip 1 kollajen yapısındadır ve biyo-emilebilir özelliktedir. Tip 1 kollajen, sığır Aşil tendonundan elde edilmektedir. Poroz kollajen ile birlikte glikozaminoglikan (GAG), skafoldun şekli, stabilitesi ve mekanik dayanıklılığını sağlar. ${ }^{[6]}$ Kollajen menisküs implant (CMI) yapısındaki GAG'lar arasında, kondriotin sülfat ve hiyaluronik asit bulunmaktadır. Biyo-emilebilir özellik, skafoldun zamanla menisküs benzeri dokuya dönüşmesi amacıyla geliştirilmiştir. ${ }^{[7]}$

- Actifit ${ }^{\circledR}$ (Orteq Ltd, Londra, Ingiltere), \%80'i geri dönüşümlü sentetik polyester (poly-caprolakton) ve kalan \%20'si poliüretandan imal edilmiştir. Polyester yapısı skafoldun esneklik ve bozunmayı önleyici etkisinden, poliüretan kısmı ise mekanik dayanıklılıktan sorumludur. Skafoldun \%80'ini poroz yapı oluşturur ve bu poroz yapı sayesinde meniskal hücrelerin skafold içine girmesi amaçlanır. ${ }^{[8]}$

Menisküsün tamirinin mümkün olmadığı durumlarda, meniskal allogreft bir diğer cerrahi tedavi yöntemidir. ${ }^{[9]}$ Ancak, meniskal skafoldlar, meniskal allogreft gerekebilen geniş defektlerde dahi kullanılarak iyileşme süresini kısaltır, allogrefte bağlı gelişebilecek enfeksiyon ve inflamasyon riskini azaltır ve greft elde edilmesini beklemeyi ortadan kaldırır. Literatürde belirtilen dezavantajları ise; pahalı olması, erken dönemde sinoviyal inflamasyon ve sığır dokusuna bağı enfeksiyon riskleridir. $\left.{ }^{[9-12}\right]$

\section{MENISKAL SKAFOLD DENEYSEL ÇALIŞMALARI}

Menisküs skafoldu ile ilgili olarak Stone ve ark., 1990'lı yılların başında emilebilen kollajen skafold üzerinde çalışmaya başlamış ve poroz yapısıyla skafold rejenere olurken hücresel gelişmeyi amaçlamışlardır. ${ }^{[13]}$ Köpeklerde yapılan ilk çalışmalarda, menisektomi sonrasında skafoldun kıkırdak hasarından koruyucu etki gösterdiği gözlenmiştir. ${ }^{[13]}$ Maher ve ark.'nın koyunlarda yaptığı çalışmada, lateral menisektomi sonrasında 42 poliüretan skafold uygulanmış ve bir yıllık takip sonucunda kıkırdakların korunduğu, ancak menisektomi yapılan kontrol grubuyla anlamlı bir farklılığın olmadığı bildirilmiştir. Aynı çalışmada yapılan histolojik incelemede, skafold içine hücresel infiltrasyonun gözlendiği belirtilmiştir. ${ }^{[14]}$ Koyunlarda yapılan bir biyomekanik çalışmada, skafoldun ekleme temas yüzeyini arttırdığı belirtilmiştir. ${ }^{[15]}$ Köpeklerde yapılan bir başka çalışmada ise skafoldun altı ayda çevre kapsüle yapıştığı ve hücresel düzeyde skafold içine doğru büyümenin başladığı gösterilmiştir.[16] Kang ve ark., meniskal hücre emdirilmiş poliglikolik asit skafoldları tavşan mediyal menisküs defektlerine yerleştirmişler ve 36 haftanın sonunda skafold içinde normal meniküs benzeri kollajen geliştiğini bildirmişlerdir. ${ }^{[17]}$ Yine mezenşimal kök hücre, kondrosit ve fibrokondrosit eklenmiş skafoldların biyomekanik, histolojik olarak normal menisküse daha yakın etki gösterdiğini belirten çalışmalar yapılmıştır. ${ }^{[18,19]}$ Kollajen ve polyester-poliüretan dışında; polilaktik asit, polidioksan gibi materyaller, skafoldun biyomekanik gücünün sağlanması ve aynı zamanda emilebilir özellik göstermesi amacıyla skafold yapısında kullanılmışlardır. ${ }^{[16,20-22]}$ Biyomekanik dayanıklılığın değerlendirildiği bir diğer çalışmada, ringer laktatlı yıkama yapılan poliüretan skafoldlara uygulanan dikişin daha dayanıklı olduğu gösterilmiştir. ${ }^{[23]}$

CMI-Menaflex ${ }^{\circledR}$ ile yapılan deneysel çalışmalarda, kıkırdak hasarı gözlenmemiş ve meniskal dokularda yenilenme görülmüştür. ${ }^{[13,24]}$ Ancak, 12 aylık uzun dönem takiplerde, subtotal menisektomi yapılan hayvan modelleri ile menisküs skafoldu yerleştirilen grup arasında anlamlı bir fark gözlenmemiştir. Martinek ve ark.'nın koyunlarda yaptığı bir çalışmada, otolog fibrokondrosit eklenmiş kollajen skafoldların vaskülarizasyonunun, ekstrasellüler matriks gelişiminin, hücre eklenmeyenlere göre daha fazla olduğu gözlenmiştir. ${ }^{[25]}$ Hansen ve ark., parsiyel menisektomi yaptıkları köpeklerde kollajen menisküs skafoldu uygulamasını takiben ilk altı haftada erken hücresel yanıtın başlayarak 1. yılın 
sonunda tamamen kaybolduğunu ve 17. ayda implantın organize fibrokondrositik dokuya dönüştüğünü gözlemişlerdir. ${ }^{[26]}$ Freymann ve ark., hiyaluronik asit, insan serum ve TGF- $\beta$ takviyeli poliglikolik asit skafold ile yaptıkları histolojik çalışmada, hiyaluronik asit ve insan serumu takviyeli grupta menisküs hücrelerinin anlamlı olarak daha fazla olduğunu gözlemişlerdir. ${ }^{[27]}$ Skafoldun poroz yapısı ile ilgili çalışmalar yapılmaktadır. De Mulder ve ark., izotropik poliüretan skafoldda, anizotropik skafoldlara göre histolojik olarak hücrelerin skafold içine ilerlemesinin daha fazla olduğunu belirtmişlerdir. ${ }^{[12]}$ Domuzlarda yapılan histolojik çalışmada, mezenşimal kök hücre içeren skofoldların koruyucu etkisinin daha iyi olduğu gösterilmiştir. ${ }^{[28]}$ Myoblast yüklü poliglikolik asit skafoldlar köpek menisküs defektlerinin rekonstrüksiyonunda kullanılmış ve skafold kalınlığının hücresiz kontrol grubuna göre anlamlı olarak daha kalın olduğu gözlenmiştir. ${ }^{[29]}$

\section{Cerrahi Teknik}

Menisküs skafold cerrahisi artroskopik olarak yapılmaktadır. Diz artroskopisi, standart anteromediyal ve anterolateral portallar ile gerçekleştirilir. Yırtılan veya patolojik menisküs, sağlıklı menisküse ulaşana kadar çıkartılır. Menisküs çıkartılması sonrası oluşan defekt değerlendirilir. Menisküs periferinin kırmızı-kırmızı veya kırmızı-beyaz bölgede olduğu görüldükten sonra, primer ile perifer duvar kanlandırılır. Defektin boyutu özel cetvel ile ölçülür ve ölçülen boyutlara göre skafold kesilir. Skafold eklem içine kanül vasıtasıyla yerleştirilir ve içten-dışa veya tümü içeride 2-0 emilmeyen dikişler ile tespit edilir.

\section{Rehabilitasyon}

Cerrahi sonrasında, diz eklemi tam ekstansiyonda olacak şekilde açılı breys kilitlenir. ilk dört hafta günde 3-4 defa $60^{\circ}$ 'ye kadar pasif fleksiyon yapılır; son iki hafta $90^{\circ}$ 'ye kadar pasiffleksiyona devam edilir. ilk altı hafta minimal yüklenmeye izin verilir. Breys 6-8 hafta sonra çıkartılır. Altıncı aydan itibaren tüm akiviteye izin verilir.

\section{KLINIKK ÇALIŞMALAR}

\section{CMI-Menaflex ${ }^{\circledR}$ Meniskal Skafold Klinik Çalışmaları}

Literatürde CMI-Menaflex ${ }^{\circledR}$ meniskal skafold ile yapılan ilk çalışmalar küçük olgu serileri şeklindedir. Biyo-emilebilir özellikte olan kollajen skafoldun cerrahi olarak yerleştirilmesi için menisküsün ön ve arka boynuzlarının sağlam olması gerekmektedir. ${ }^{[30,31]}$ Rodkey ve ark., 1999 yılında CMI-Menaflex ${ }^{\circledR}$ uygulanan sekiz hastanın iki yıllık klinik sonuçlarında, tüm hastalarda
Lysholm ve Tegner aktivite klinik skorlarında artış saptamışlar ve alınan biyopsi örneklerinde gelişen yeni menisküs dokusunda fibrokartilajinöz hücreler tespit etmişler, radyolojik takiplerde herhangi bir dejeneratif değişikliğe gidiş tespit etmemişlerdir. ${ }^{[30]}$ Zaffagnini ve ark., CMI-Menaflex ${ }^{\circledR}$ ile tedavi edilen 43 menisektomi hastasının iki yıllık klinik sonuçlarını yayımlamışlar ve diz fonksiyonlarında anlamlı artış saptamışlardır; ancak, kronik menisküs yaralanmaları, yüksek kilo ve ön çapraz bağ yaralanması gibi eşlik eden yaralanmaların olduğu durumlara sahip olan hastaların sonuçlarının daha kötü olduğunu bildirmişlerdir. ${ }^{[32]}$ Sekiz hastanın 6-8 yıl takip edildiği uzun dönem bir çalışmada, hastaların fonksiyonel diz skorlarında anlamlı artış olduğu; ancak iki hastada skorların 2. yıldaki skorlarına göre daha düşük olduğu bildirilmiştir. ${ }^{[33]}$

Literatürde, büyük olgu serilerini kapsayan çalışmalar da bulunmaktadır. Rodkey ve ark., tedavi edilemeyen parsiyel menisküs yırtığı nedeniyle CMI-Menaflex ${ }^{\circledR}$ uygulanan 311 hastayı kapsayan ve skafold uygulanan hastalar ile parsiyel menisektomi dışında hiçbir tedavi yapılmayan hastaların sonuçlarını karşılaştırdıkları çok merkezli randomize klinik çalışmalarında, beş yıl sonunda iki grup arasında anlamlı bir klinik fark bulamamış, ancak bir yıl sonra yaptıkları artroskopilerde menisküs rejenerasyonunun CMI uygulanan grupta belirgin olarak daha fazla görüldüğünü saptamışlardır. Ancak, cerrahi sonrası 5. yılda yapılan manyetik rezonans (MR) görüntülemelerinde belirgin bir farklılık ve yeni menisküs formasyonu saptamamışlardır. Aynı çalışmada, akut yaralanma sonrası skafold uygulanan hastaların sonuçlarının anlamlı olarak daha iyi bulunduğunu bildirmişlerdir. ${ }^{[34]}$ Zaffagnini ve ark.'nın yaptığı uzun dönem takipli bir çalışmada, literatürdeki CMI uygulanmasını takiben yapılan MR görüntüleme sonuçları değerlendirilmiş ve skafold boyutlarında zamanla küçülme tespit edilmiştir. illk altı ayda boyutlarda herhangi bir küçülme saptanmazken, 10 yıl sonunda hastaların >\%90'ında skafold boyutlarında küçülme tespit edilmiştir. ${ }^{[35]}$ Yine Zaffagnini ve ark.'nın yaptığı başka bir çalışmada, lateral menisküse uygulanan CMI kollajen skafoldların iki yıllık takibinde fonksiyonel diz skorlarında anlamlı artış ve hastaların \%96'sında iyi/ mükemmel sonuç saptanırken, yapılan MR takiplerinde hastaların \%12,5'inde skafold tamamen emildiği, hastaların \%37,5'inde ise tamamen matüre olduğu bildirilmiştir. ${ }^{[36]}$ Parsiyel ve total menisektomi nedeniyle CMI kollajen menisküs skafoldu uygulanan 77 hastanın fonksiyonel diz skorlarında hastaların \%90'ında anlamlı artış saptanmış, ancak yapılan MR takiplerinde üç (\%5) hastada komple rezorpsiyon, 55 (\%92) hastada parsiyel rezorpsiyon olduğu ve üç (\%5) hastada ise tamamen korunduğu gözlenmiştir. ${ }^{[37]}$ 
Kollajen bazlı meniskal skafoldlar ile yapılan ve uzun dönem takip içeren çalışmalar, önemli bilgiler vermektedir. Bulgheroni ve ark., tedavi edilmeyen menisküs yırtığı nedeniyle artroskopik menisektomi uygulanan 34 hastaya (ort. yaş 39) CMI-Menaflex ${ }^{\circledR}$ uygulamışlar ve hastaları beş yıl süreyle fonksiyonel ve radyolojik olarak takip etmişlerdir. Bu cerrahi için seçilen hastalara skafold uygulama endikasyonları, tedavi edilemeyen menisküs yırtığı sonrasında menisküsün $\% 25^{\prime}$ i alınmış hastalarda devam eden ağı olması olarak belirlemişlerdir. Hastaların beş yıl sonundaki Lysholm skoru ve Tegner aktivite skorlarında cerrahi öncesine göre anlamlı artış saptamışlar, eklem yüzeyinde ilerleyici dejeneratif değişiklikler saptamamışlardır. Ancak, yapılan MR kontrollerinde implant boyutlarında küçülme ve sinyallerde sağlam menisküse göre bir miktar azalma saptamışlardır. Sekiz hastaya ikinci artroskopi uygulanmış ve alınan histopatolojik örneklerde skafold içinde damarlanma ve fibrokartilajinöz hücreler saptanmıştır. ${ }^{[38]}$ Steadman ve ark. da CMI uyguladıkları hastaların biyopsilerinde herhangi bir enfeksiyon, inflamasyon ve immün reaksiyon bulgusu olmadan skafold içinde fibrokartilaj ve ekstrasellüler matriks oluşumunu gözlemişlerdir. ${ }^{[31]}$ Monllau ve ark., CMI skafoldu ile tedavi ettikleri 25 hastanın en az 10 yıllık fonksiyonel ve radyolojik sonuçlarını yayımlamışlar ve hastaların \%83'ünde iyi ve mükemmel sonuç, vizüel analog skala (VAS) ve Lysholm diz skorlarında anlamlı artış saptamışlardır. Yapılan MR takiplerine, skafold boyutunda küçülme ve menisküs ile skafold arasında parsiyel birleşme tespit etmişlerdir. ${ }^{[39]}$

Meniskal skafoldlar, diz içi diğer bağ yaralanmaları ile birlikte olan menisküs yırtıklarında da kullanılabilir. Bulgheroni ve ark., menisküs yırtığı ile birlikte ön çapraz bağ (ÖÇB) yırtığı olan 34 hastanın 17'sine ÖÇB rekonstrüksiyonu ile birlikte parsiyel menisektomi, kalanına da CMI ile birlikte rekonstrüksiyon uygulamış ve fonksiyonel diz skorları olarak her iki grup arasında anlamlı bir farklııık bulmamışlardır. Akut menisküs yırtığı nedeniyle CMI uygulanan hastalarda daha az laksite saptamışlar, ancak kronik menisküs yırtığı nedeniyle CMI ile birlikte ÖÇB rekonstrüksiyonu uygulanan grupta parsiyel menisektomi yapılan hastalara göre daha kötü ağrı skorları olduğunu belirtmişlerdir.

\section{Actifit ${ }^{\circledR}$ Meniskal Skafold Klinik Çalışmaları}

Sentetik polyester yapıdaki meniskal skafold olan Actifit $^{\circledR}$, poroz yapısı sayesinde fibrokartilajinöz hücrelerin skafold içine doğru yerleşmesini sağlar. Biyoemilebilir yapıdaki skafold hidroliz ile çözülmeye başlar ve beş yıldan fazla bir sürede çözünür. ${ }^{[40]}$ Literatürde, Actifit $^{\circledR}$ poliyester-poliüretan meniskal skafold sonuçlarını bildiren birçok klinik çalışma bulunmaktadır
(Tablo 1). Verdonk ve ark., poliüretan skafold uyguladıkları hastaların 3., 6. ve 12. aylarda skafold içine doku ilerlemesini dinamik kontrastlı MR görüntüleme ile incelemişler ve hastaların \%81,4'ünde 3. ayda, $\% 97,7$ 'sinde ise 12 . ayda meniskal doku oluştuğunu ve gerçekleştirdikleri ikincil artroskopilerde aldıkları örneklerin histolojik incelemesinde vaskülarizasyon ve fibrokondroblast benzeri hücreler bulunduğunu gözlemişlerdir. ${ }^{[41]}$ Baynat ve ark., menisektomi sonrasında geniş defekte sahip olan 18 hastayı (13 hastada mediyal menisektomi, beş hastada lateral menisektomi nedeniyle opere) Actifit ${ }^{\circledR}$ menisküs skafoldu ile tedavi etmişlerdir. Hastaların 12'sinde, ön çapraz bağ rekonstrüksiyonu ve/veya tibial osteotomi cerrahisi uygulanmıştır. Hastaların \%92'sinde Lysholm diz skorları mükemmel olarak bulunmuş ve hastaların MR görüntülemelerinde cerrahi sonrası kıkırdak hasarı veya osteoartrite gidiş saptanmamıştır. Üç hastanın cerrahi sonrası birinci yılında yapılan biyopsilerinde, polimer içinde kondrosit ve fibrokondrosit gelişimi gösterilmiştir. ${ }^{[42]}$

Yapılan çalışmalarda, Actifit ${ }^{\circledR}$ uygulanmasını takiben MR takiplerinde menisküs skafold boyutunda küçülme ve skafold ekstrüksiyonu görülebildiği saptanmıştır. ${ }^{[43]}$

Hernandez ve ark., Actifit ${ }^{\circledR}$ menisküs skafoldu uygulanmış ortalama yaşı 30,6 olan 10 hastanın ortalama 34,7 ay takip ettikleri fonksiyonel diz skorları ve radyolojik sonuçlarını bildirmişlerdir. Hastaların yapılan takiplerinde Lysholm, diz incinme ve osteoartrit sonuç sonuç skor (the knee injury and osteoarthritis outcomes score, KOOS)'larında anlamlı artış saptamışlar, ancak yapılan MR takiplerinde skafold boyutlarında küçülme ve sinyal şiddetinde azalma görmüş ve hiçbir hastada normal menisküs sinyaline ulaşamadıklarını belirtmişlerdir. Üç hastada, cerrahiyi takiben akut hemoraji nedeniyle artrosentez uygulamış ve bir hastada takiplerde dejeneratif değişiklikler saptamışlardır. ${ }^{[44]}$ De Coninck ve ark., Actifit ${ }^{\circledR}$ polikarbonat-üretan skafoldun yüklenme ve hareket halindeki durumunu açık MR'de incelemişler ve opere olmayan taraftaki menisküsün kinematik özellikleri ile karşılaştırmışlardır. Femoral roll-back ve yüklenme esnasında fark bulamamışlar, ancak fleksiyonda yapılan ön-arka hareketlerde, polikarbonat skafold uygulanan tarafta anlamlı olarak az hareket saptamışlardır. ${ }^{[4]}$ Radyal yer değiştirme, meniskal skafold uygulaması sonrasında görülebilir. De Coninck ve ark., özellikle mediyal skafoldun laterale göre daha fazla radyale yer değiştirdiğini, ancak bunun klinik olarak anlamlı bir etkisinin olmadığını belirtmişlerdir. ${ }^{[46]}$ Efe ve ark., poliüretan meniskal skafold uygulanan 10 hastanın ortalama bir yıllık takiplerinde tüm hastaların fonksiyonel diz skorlarında anlamlı artış saptamışlar, yapılan MR görüntülemelerinde dört hastada koronal 
Tablo 1. Literatürdeki meniskal skafold uygulaması ile ilgili klinik yayınlar

\begin{tabular}{|c|c|c|c|c|c|c|c|}
\hline Yazar & Yıl & Skafold tipi & Mediyal/Lateral & Ort. Yaş & Cinsiyet E/B & Takip Süresi[42] & Sonuç \\
\hline Verdonk ${ }^{[51]}$ & 2012 & Polyester & $34 / 28$ & 31 & $39 / 13$ & 12 & $\begin{array}{l}\text { Hastaların \%17,3'ünde } \\
\text { başarısızık bildirildi }\end{array}$ \\
\hline $\mathrm{Efe}^{[47]}$ & 2012 & Polyester & $10 / 0$ & 29 & $8 / 2$ & 12 & $\begin{array}{l}\text { Parsiyel mediyal menisküs } \\
\text { yırtıklarında başarılı tedavi }\end{array}$ \\
\hline De Coninck ${ }^{[46]}$ & 2013 & Polyester & $18 / 8$ & 35 & $14 / 12$ & 24 & $\begin{array}{l}\text { Mediyal skafold laterale } \\
\text { göre daha fazla radyale yer } \\
\text { değiştirdi ancak bunun klinik } \\
\text { anlamlı etkisi yok }\end{array}$ \\
\hline Kon $^{[69]}$ & 2014 & Polyester & $13 / 5$ & 45 & $11 / 7$ & 24 & $\begin{array}{l}\text { Fonksiyonel diz skorlarında } \\
\text { anlamlı artış }\end{array}$ \\
\hline Bouyarmane ${ }^{[11]}$ & 2014 & Polyester & $0 / 54$ & 28 & $37 / 17$ & 24 & $\begin{array}{l}\text { Skafold güvenli ve efektif } \\
\text { tedavi }\end{array}$ \\
\hline Schuttler ${ }^{[3]]}$ & 2014 & Polyester & $18 / 0$ & 32,5 & - & 24 & $\begin{array}{l}\text { Skafold ekstrüksiyonu, klinik } \\
\text { sonucunu etkilemez }\end{array}$ \\
\hline Baynat $^{[42]}$ & 2015 & Polyester & $13 / 5$ & $20-46$ & $13 / 5$ & 24 & $\begin{array}{l}\text { Histolojik olarak } 1 \text {. yılda } \\
\text { skafold içine hücre in-growth } \\
\text { saptandı }\end{array}$ \\
\hline Gelber ${ }^{[49]}$ & 2015 & Polyester & $30 / 0$ & 45,1 & $21 / 9$ & 31,2 & $\begin{array}{l}\text { Tibial osteotomi ile birlikte } \\
\text { skafold uygulaması klinik } \\
\text { sonuçları etkilemez }\end{array}$ \\
\hline Monllau[48] & 2018 & Polyester & $21 / 11$ & 41.3 & $25 / 7$ & 70,5 & $\begin{array}{l}\text { Hastaların fonksiyonel } \\
\text { sonuçları iyi. Ancak MR'de } \\
\text { beklendiğinden dar yapıda } \\
\text { görüntü }\end{array}$ \\
\hline Monllou[39] & 2011 & Kollajen & $5 / 15$ & 29,2 & $20 / 5$ & 11.1 & $\begin{array}{l}\text { Hastaların \%8'inde } \\
\text { başarısızlık }\end{array}$ \\
\hline Steadman ${ }^{[31]}$ & 2005 & Kollajen & $8 / 0$ & 40 & $8 / 0$ & 69,6 & $\begin{array}{l}\text { Beş yıl sonunda fonksiyonel } \\
\text { diz skorlarında anlamlı artış }\end{array}$ \\
\hline Bulgheroni ${ }^{[38]}$ & 2010 & Kollajen & -- & 39 & $25 / 9$ & 60 & $\begin{array}{l}\text { CMI beş yılda tamamen } \\
\text { resorbe oldu }\end{array}$ \\
\hline Linke ${ }^{[6]}$ & 2006 & Kollajen & $60 / 0$ & 41,6 & 60 & 24 & $\begin{array}{l}\text { Hastaların \%34,8'inin CMI } \\
\text { tamemen iyileşti. }\end{array}$ \\
\hline Stone ${ }^{[70]}$ & 1997 & Kollajen & & 39,3 & $8 / 2$ & 36 & $\begin{array}{l}\text { Otuz altı ayda eklem } \\
\text { aralığında daralma } \\
\text { gözlenmedi }\end{array}$ \\
\hline Zaffagninil[71] & 2011 & Kollajen & $33 / 0$ & 40 & $33 / 0$ & 135 & $\begin{array}{l}\text { Skafold uygulanan hastalarda } \\
\text { uygulanmayanlara göre } 1,7 \\
\text { mm daha az eklem aralığında } \\
\text { azalma }\end{array}$ \\
\hline Rodkey ${ }^{[34]}$ & 2008 & Kollajen & $160 / 0$ & 39 & - & 59 & $\begin{array}{l}\text { Yapılan biyopsilerde skafold } \\
\text { yapısında fibrokondrosit } \\
\text { benzeri hücre organizasyonu }\end{array}$ \\
\hline
\end{tabular}

E, erkek; B, bayan.

ve sagittal planda skafold ile menisküs dokusu arasında gap oluştuğunu ve bir skafoldun bir yıl sonunda tamamen rezorbe olduğunu bildirmişlerdir. ${ }^{[47]}$ Monllau ve ark., poliüretan meniskal skafold uyguladıkları hastaların minimum beş yıllık sonuçlarını yayımlamışlar ve tüm hastalarda fonksiyonel olarak anlamlı iyileşme bulduklarını, ancak MR görüntülerinde menisküsün beklediklerinden daha ince yapıda olduğunu ve menisküs dokusunun sağlıklı menisküs gibi olmadığını belirtmişlerdir. ${ }^{[48]}$

Varus dizlerde menisküs skafoldu uygulanması planlanan olgularda, skafold üzerine gelişebilecek stresi azaltmak amacıyla yüksek tibial osteotomi (YTO) gerekebilir. Gelber ve ark., semptomatik varusu ve 
menisküs yırtığı olan 60 hastanın 30'una YTO ve menisektomi, kalan 30 hastaya YTO ve Actifit ${ }^{\circledR}$ uygulamış ve bu hastaların fonksiyonel skorları ile hasta memnuniyet skorlarını karşılaştırdıklarında anlamlı bir farklılık olmadığını saptamışlardır. ${ }^{49]}$

Menisküs allogreftleri, özellikle geniş menisküs defektine sahip genç hastalarda uygulanabilen tedavi yöntemlerinden birisidir. Ancak, doku bankasına ihtiyaç duyulması ve elde edilen menisküs boyutlarının sınırlı olması nedeniyle, bu tedaviye alternatif olarak meniskal skafoldlar kullanılabilir. Taze-dondurulmuş meniskal allogreft, taze allogreft ve meniskal skafold uygulanan hastaların histolojik ve immünohistokimyasal sonuçlarının incelendiği bir çalışmada, taze meniskal allogreft ve skafold grubunda, menisküs doğal yapısında bulunan fibrokondrositlerde anlamlı artış ve morfolojik yapısında rejenerasyon saptanmış ve taze allogreft bulunamayan durumlarda meniskal skafoldun alternatif olabileceği bildirilmiştir. ${ }^{[50]}$ Verdonk ve ark., yaptıkları çok merkezli çalışmada, Actifit ${ }^{\circledR}$ uyguladıkları 34 mediyal menisküs ve 18 lateral menisküs defektine sahip hastanın ortalama iki yıllık takiplerinde, hastaların \%17,3'ünde başarısız sonuç elde ettiklerini, ancak kalan hastaların fonksiyonel diz skorlarında anlamlı artış olduğunu gözlemişlerdir. ${ }^{[51]}$

Poliüretan skafoldların sonuçlarının değerlendirildiği çalışmalar genellikle mediyal menisküs yırtıkları olmasına rağmen, bunlar lateral menisküs yırtıklarının tedavisinde de kullanılmaktadır. Bouyarmane ve ark.'nın yaptıkları, lateral menisküsün segmental defektlerinin Actifit ${ }^{\circledR}$ poliüretan skafold ile tedavi edildiği 54 hastalık ileriye dönük multisentrik çalışmada, tüm hastaların VAS, KOOS ve IKDC (International Knee Documentation Committee) skorlarında minimum iki yıllık takiplerde anlamlı artış saptamışlardır. ${ }^{[11]}$ Bulgheroni ve ark., Actifit $^{\circledR}$ uygulanan 19 hastanın dokuzuna 12. ve 24 . ayda yapılan artroskopilerinde skafoldun çevre dokulara entegre olduğunu gözlemlemişler ve poliüretan skafoldların menisküs defektlerinin tedavisinde kullanılabilecek uygun bir tedavi yöntemi olduğunu saptamışlardır. ${ }^{[52]}$

\section{Karşılaştırmalı Klinik Çalışmalar}

Son yıllarda, meniskal skafoldun klinik sonuçlarının karşılaştırıldığı çalışmalarda, hangi skafoldun daha iyi klinik sonuçlarının olduğu değerlendirilmek istenmektedir. Spencer ve ark., menisküs skafoldu uygulanan toplam 23 hastanın (Actifit ${ }^{\circledR}$ (11 hasta) ve CMI (12 hasta)) minimum bir yıllık takiplerinde, hastaların \%91,3'ünde KOOS, IKDC ve Lysholm fonksiyonel sonuçlarında anlamlı artış saptamışlar ve son takip MR incelemelerinde kıkırdak hasarlanması saptamamışlardır. ${ }^{[53]}$ Uzun dönem takipli bir başka çalışmada, beş yıllık takipte, poliüretan skafold uygulanan hastalarda implant başarısızlık oranının $\% 46,7$ olduğu belirtilmiştir. ${ }^{[54]}$ Kollajen ve sentetik bazlı meniskal skafoldların sonuçlarının karşılaştırıldığı bir çalışmada, minimum iki yıllık takipli hastalara artroskopik biyopsi yapılmış ve her iki grubun da fonksiyonel sonuçlarında anlamlı artış ve MR ile yapılan takiplerinde kıkırdak hasarı olmadığı, ancak yapılan biyopsilerde CMI grubunda vasküler damarlanma görünmesine rağmen, Actifit ${ }^{\circledR}$ grubunda avasküler alanlar olduğunu belirtmişlerdir. ${ }^{[55]}$

\section{SISTEMATIK ANALIZLER}

Poliüretan ve kollajen skafold sonuçlarının karşılaştırıldığı bir sistematik incelemede, klinik sonuçların her iki implanttada benzer, MR'de kollajen bazlı skafold sinyalinin daha iyi olduğu belirtilmiştir. ${ }^{[56]} \mathrm{Bir}$ başka karşılaştırmalı meta-analizde poliüretan bazlı skafoldların klinik sonuçlarının daha iyi olduğu, ancak kıkırdak aşınmasının daha fazla ve meniskal ekstrüksiyonun daha fazla olduğu gösterilmiştir. ${ }^{[57]}$ Yapılan bir başka meta-analizde, meniskal skafold sonrası ortalama başarısızılı \%5,6 ve re-operasyon oranı $\% 6,9$ olarak bildirilmiş ve bunlar meniskal allogreft sonuçları ile karşılaştırılmıştır. Buna göre, meniskal allogreft cerrahisi sonrası başarısızlık oranı $\% 18,7$ ve re-operasyon oranı $\% 31,3$ olduğu belirtilmiştir. ${ }^{[58]}$

\section{MENISKAL SKAFOLDLARDA YENILIKLER}

Menisküs skafoldlarının yük aktarım görevini arttırmak ve dize yerleştirilmesi sonrasında hücresel boyutta normal menisküs özelliklerini gösterebilmesini sağlamak amacıyla çalışmalar devam etmektedir. Oda ve ark., menisküs defektlerinin skafold ile tedavisinde hücresel aktivite rejenerasyonunu arttırmak amacıyla, mezenşimal kök hücreden zengin infrapatellar yağ yastığı ile skafold uygulaması fikrini ortaya atmışlar ve tavşanlar ile yaptıkları çalışmada antikor yanıtının azaldığını ve matriks metalloproteinaz sentezinde artış olduğunu tespit etmişlerdir. ${ }^{[59]}$ Menisküs skafoldunu hücresel olarak aktifleştirmek ve normal menisküse benzer bir matriks elde etmek amacıyla, doku mühendisliği çalışmaları yapılmaktadır. ${ }^{60]}$ Zellner ve ark., kollajen yapıdaki skafoldu trombositten zengin plazma ve mezenşimal kök hücre emdirilmiş skafold ile tavşanlarda yaptıkları histolojik çalışmada, mezenşimal hücreli skafoldun daha stabil ve efektif olduğunu belirtmişlerdir. ${ }^{[61]}$. Weinand ve ark., allojenik ve otojenik meniskal hücreleri skafold içine yerleştirip, domuzlarda parsiyel menisküs defektinin tamirini yapmışlar ve skafold uygulanmayan kontrol grubunda hiç iyileşme olmamasına rağmen, allojenik 
hücre uygulanan grupta tüm menisküslerde iyileşme saptamışlardır. ${ }^{[62]}$

Kollajen ve polyester dışında skafold ürünleri de geliştirilmeye çalışılmaktadır. Gruchenberg ve ark., ipek fibrin menisküs skafoldunu koyunlarda uygulamışlar ve altı aylık takiplerinde skafold ile menisektomi grubu arasında kıkırdak dejenerasyonu açısından anlamlı bir fark bulmamışlardır. ${ }^{[63]}$ Menisküs skafoldunun 3-boyutlu yapısının çok katlı nano-fibril katmanlı haline meniskal hücrelerin yerleştirildiği, polilaktik asit-caprolakton yapısında, üç boyutlu polimer-hiyaluran yapısında ve jelatin-chitosan çapraz bağlı yeni skafold türleri üzerine çalışılmaktadır. ${ }^{[64-67]}$ Meniskal allogreftin immünolojik etkilerinin azaltılması amacıyla, hücresiz hale getirilerek biyomekanik özellikleri skafold benzeri etkiyle kullanılabilecek allogreftten elde edilen skafoldlar üzerinde de çalışılmaktadır. ${ }^{[68]}$ Meniskal skafoldlar genellikle vaskülaritesi yüksek meniskal bölge yırtıklarında kullanılmasına rağmen, Pabbruwe ve ark., beyaz-beyaz meniskal yırtıklarda mezenşimal kök hücreli kollajenöz skafoldların sandviç şeklinde tamiri ile mekanik açıda güçlü meniskal dokular elde edilebileceğini göstermişlerdir. ${ }^{[19]}$

\section{KAYNAKLAR}

1. Hasan J, Fisher J, Ingham E. Current strategies in meniscal regeneration. J Biomed Mater Res B Appl Biomater 2014;102(3):619-34. Crossref

2. Sanchez-Adams J, Willard VP, Athanasiou KA. Regional variation in the mechanical role of knee meniscus glycosaminoglycans. J Appl Physiol 2011;111(6):1590-6. Crossref

3. Nepple JJ, Dunn WR, Wright RW. Meniscal repair outcomes at greater than five years: a systematic literature review and meta-analysis. J Bone Joint Surg Am 2012;94(24):2222-7. Crossref

4. Greis PE, Bardana DD, Holmstrom MC, Burks RT. Meniscal injury: I. Basic science and evaluation. J Am Acad Orthop Surg 2002;10(3):168-76. Crossref

5. Petty CA, Lubowitz JH. Does arthroscopic partial meniscectomy result in knee osteoarthritis? A systematic review with a minimum of 8 years' follow-up. Arthroscopy 2011;27(3):419-24. Crossref

6. Linke RD, Ulmer M, Imhoff $A B$. Replacement of the meniscus with a collagen implant (CMI). Oper Orthop Traumatol 2006;18(5-6):453-62. Crossref

7. Stone KR, Rodkey WG, Webber R, McKinney L, Steadman JR. Meniscal regeneration with copolymeric collagen scaffolds. In vitro and in vivo studies evaluated clinically, histologically, and biochemically. Am J Sports Med 1992;20(2):104-11. Crossref

8. Rongen JJ, van Tienen TG, van Bochove B, Grijpma DW, Buma P. Biomaterials in search of a meniscus substitute. Biomaterials 2014;35(11):3527-40. Crossref

9. Filardo G, Andriolo L, Kon E, de Caro F, Marcacci M. Meniscal scaffolds: results and indications. A systematic literature review. Int Orthop 2015;39(1):35-46. Crossref
10. Tucker B, Khan W, Al-Rashid M, Al-Khateeb H. Tissue engineering for the meniscus: a review of the literature. Open Orthop 2012;6(1):348-51. Crossref

11. Bouyarmane $H$, Beaufils $P$, Pujol N, Bellemans J, Roberts $S$, Spalding T, Zaffagnini S, Marcacci M, Verdonk P, Womack $\mathrm{M}$, Verdonk R. Polyurethane scaffold in lateral meniscus segmental defects: clinical outcomes at 24 months follow-up. Orthop Traumatol Surg Res 2014;100(1):153-7. Crossref

12. de Mulder EL, Hannink G, Verdonschot N, Buma P. Effect of polyurethane scaffold architecture on ingrowth speed and collagen orientation in a subcutaneous rat pocket model. Biomed Mater 2013;8(2):025004. Crossref

13. Stone KR, Rodkey WG, Webber RJ, McKinney L, Steadman JR. Future directions. Collagen-based prostheses for meniscal regeneration. Clin Orthop Relat Res 1990;(252):129-35. Crossref

14. Maher SA, Rodeo SA, Doty SB, Brophy R, Potter H, Foo LF, Rosenblatt L, Deng XH, Turner AS, Wright TM, Warren RF. Evaluation of a porous polyurethane scaffold in a partial meniscal defect ovine model. Arthroscopy 2010;26(11):15109. Crossref

15. Brophy RH, Cottrell J, Rodeo SA, Wright TM, Warren RF, Maher SA. Implantation of a synthetic meniscal scaffold improves joint contact mechanics in a partial meniscectomy cadaver model. J Biomed Mater Res A 2010;92A(3):1154-61. Crossref

16. Tienen TG, Heijkants RG, de Groot JH, Pennings AJ, Schouten AJ, Veth RP, Buma P. Replacement of the knee meniscus by a porous polymer implant: a study in dogs. Am J Sports Med 2006;34(1):64-71. Crossref

17. Kang SW, Son SM, Lee JS, Lee ES, Lee KY, Park SG, Park JH, Kim BS. Regeneration of whole meniscus using meniscal cells and polymer scaffolds in a rabbit total meniscectomy model. J Biomed Mater Res A 2006;78A(3):638-51. Crossref

18. Buma $P$, Ramrattan NN, van Tienen TG, Veth RP. Tissue engineering of the meniscus. Biomaterials 2004;25(9):152332. Crossref

19. Pabbruwe MB, Kafienah W, Tarlton JF, Mistry S, Fox DJ, Hollander AP. Repair of meniscal cartilage white zone tears using a stem cell/collagen-scaffold implant. Biomaterials 2010;31(9):2583-91. Crossref

20. van Tienen TG, Heijkants RG, Buma P, de Groot JH, Pennings AJ, Veth RP. Tissue ingrowth and degradation of two biodegradable porous polymers with different porosities and pore sizes. Biomaterials 2002;23(8):1731-8. Crossref

21. Zur G, Linder-Ganz E, Elsner JJ, Shani J, Brenner O, Agar G, Hershman EB, Arnoczky SP, Guilak F, Shterling A. Chondroprotective effects of a polycarbonate-urethane meniscal implant: histopathological results in a sheep model. Knee Surg Sports Traumatol Arthrosc 2011;19(2):255-63. Crossref

22. Ramrattan NN, Heijkants RG, van Tienen TG, Schouten AJ, Veth RP, Buma P. Assessment of tissue ingrowth rates in polyurethane scaffolds for tissue engineering. Tissue Eng 2005;11(7-8):1212-23. Crossref

23. Hoburg A, von Roth P, Roy-Ali S, Ode JE, Wulsten D, Jung TM, Gwinner C. Biomechanical performance of the Actifit ${ }^{\circledR}$ scaffold is significantly improved by selection of irrigation fluid. Arch Orthop Trauma Surg 2018;138(4):537-42. Crossref

24. Maher SA, Rodeo SA, Potter HG, Bonassar LJ, Wright TM, Warren RF. A pre-clinical test platform for the functional evaluation of scaffolds for musculoskeletal defects: the meniscus. HSS J 2011;7(2):157-63. Crossref 
25. Martinek V, Ueblacker $P$, Braun $K$, Nitschke S, Mannhardt R, Specht K, Gansbacher B, Imhoff AB. Second generation of meniscus transplantation: in-vivo study with tissue engineered meniscus replacement. Arch Orthop Trauma Surg 2006;126(4):228-34. Crossref

26. Hansen R, Bryk E, Vigorita V. Collagen scaffold meniscus implant integration in a canine model: a histological analysis. J Orthop Res 2013;31(12):1914-9. Crossref

27. Freymann $U$, Endres $M$, Goldmann $U$, Sittinger $M$, Kaps $C$. Toward scaffold-based meniscus repair: effect of human serum, hyaluronic acid and TGF-ß3 on cell recruitment and re-differentiation. Osteoarthritis Cartilage 2013;21(5):77381. Crossref

28. Moriguchi $Y$, Tateishi $K$, Ando $W$, Shimomura $K$, Yonetani Y, Tanaka Y, Kita K, Hart DA, Gobbi A, Shino K, Yoshikawa $\mathrm{H}$, Nakamura N. Repair of meniscal lesions using a scaffoldfree tissue-engineered construct derived from allogenic synovial MSCs in a miniature swine model. Biomaterials 2013;34(9):2185-93. Crossref

29. Gu Y, Zhu W, Hao Y, Lu L, Chen Y, Wang Y. Repair of meniscal defect using an induced myoblast-loaded polyglycolic acid mesh in a canine model. Exp Ther Med 2011;3(2):293-8. Crossref

30. Rodkey WG, Steadman JR, Li ST. A clinical study of collagen meniscus implants to restore the injured meniscus. Clin Orthop Relat Res 1999;(367 Suppl):S281-92. Crossref

31. Steadman JR, Rodkey WG. Tissue-engineered collagen meniscus implants: 5- to 6-year feasibility study results. Arthroscopy 2005;21(5):515-25. Crossref

32. Zaffagnini S, Grassi A, Marcheggiani Muccioli GM, Holsten D, Bulgheroni P, Monllau JC, Berbig R, Lagae K, Crespo R, Marcacci M. Two-Year Clinical Results of Lateral Collagen Meniscus Implant: A Multicenter Study. Arthroscopy 2015;31(7):1269-78. Crossref

33. Zaffagnini S, Giordano G, Vascellari A, Bruni D, Neri MP, lacono F, Kon E, Presti ML, Marcacci M. Arthroscopic collagen meniscus implant results at 6 to 8 years follow up. Knee Surg Sports Traumatol Arthrosc 2007;15(2):175-83. Crossref

34. Rodkey WG, DeHaven KE, Montgomery WH 3rd, Baker CL Jr, Beck CL Jr, Hormel SE, Steadman JR, Cole BJ, Briggs KK. Comparison of the collagen meniscus implant with partial meniscectomy. A prospective randomized trial. J Bone Joint Surg Am 2008;90(7):1413-26. Crossref

35. Zaffagnini S, Grassi A, Marcheggiani Muccioli GM, Bonanzinga T, Nitri M, Raggi F, Ravazzolo G, Marcacci M. MRI evaluation of a collagen meniscus implant: a systematic review. Knee Surg Sports Traumatol Arthrosc 2015;23(11):3228-37. Crossref

36. Zaffagnini S, Marcheggiani Muccioli GM, Bulgheroni $P$, Bulgheroni E, Grassi A, Bonanzinga T, Kon E, Filardo $G$, Busacca M, Marcacci M. Arthroscopic collagen meniscus implantation for partial lateral meniscal defects: a 2-year minimum follow-up study. Am J Sports Med 2012;40(10):2281-8. Crossref

37. Hirschmann MT, Keller L, Hirschmann A, Schenk L, Berbig R, Luthi U, Amsler F, Friederich NF, Arnold MP. One-year clinical and MR imaging outcome after partial meniscal replacement in stabilized knees using a collagen meniscus implant. Knee Surg Sports Traumatol Arthrosc 2013;21(3):740-7. Crossref

38. Bulgheroni P, Murena L, Ratti C, Bulgheroni E, Ronga $M$, Cherubino P. Follow-up of collagen meniscus implant patients: clinical, radiological, and magnetic resonance imaging results at 5 years. Knee 2010;17(3):224-9. Crossref
39. Monllau JC, Gelber PE, Abat F, Pelfort X, Abad R, Hinarejos $P$, Tey M. Outcome after partial medial meniscus substitution with the collagen meniscal implant at a minimum of 10 years' follow-up. Arthroscopy 2011;27(7):933-43. Crossref

40. Brophy RH, Matava MJ. Surgical options for meniscal replacement. J Am Acad Orthop Surg 2012;20(5):265-72. Crossref

41. Verdonk R, Verdonk P, Huysse W, Forsyth R, Heinrichs EL. Tissue ingrowth after implantation of a novel, biodegradable polyurethane scaffold for treatment of partial meniscal lesions. Am J Sports Med 2011;39(4):774-82. Crossref

42. Baynat $C$, Andro C, Vincent JP, Schiele P, Buisson P, Dubrana F, Gunepin FX. Actifit ${ }^{\circledR}$ synthetic meniscal substitute: experience with 18 patients in Brest, France. Orthop Traumatol Surg Res 2014;100(8 Suppl):S385-9. Crossref

43. Schuttler KF, Pöttgen S, Getgood A, Rominger MB, FuchsWinkelmann S, Roessler PP, Ziring E, Efe T. Improvement in outcomes after implantation of a novel polyurethane meniscal scaffold for the treatment of medial meniscus deficiency. Knee Surg Sports Traumatol Arthrosc 2015;23(7):1929-35. Crossref

44. Martin-Hernandez C, Ranera-Garcia M, Diaz-Martinez JV, Muniesa-Herrero MP, Floria-Arnal LJ, Osca-Guadalajara M, Garcia-Aguilera D. Results of polyurethane implant for persistent knee pain after partial meniscectomy with a minimum of two years follow-up. Rev Esp Cir Ortop Traumatol 2015;59(1):44-51. Crossref

45. De Coninck T, Elsner JJ, Linder-Ganz E, Cromheecke M, Shemesh M, Huysse W, Verdonk R, Verstraete K, Verdonk P. In-vivo evaluation of the kinematic behavior of an artificial medial meniscus implant: A pilot study using open-MRI. Clin Biomech 2014;29(8):898-905. Crossref

46. De Coninck T, Huysse W, Willemot L, Verdonk R, Verstraete $\mathrm{K}$, Verdonk P. Two-year follow-up study on clinical and radiological outcomes of polyurethane meniscal scaffolds. Am J Sports Med 2013;41(1):64-72. Crossref

47. Efe T, Getgood A, Schofer MD, Fuchs-Winkelmann S, Mann D, Paletta JR, Heyse TJ. The safety and short-term efficacy of a novel polyurethane meniscal scaffold for the treatment of segmental medial meniscus deficiency. Knee Surg Sports Traumatol Arthrosc 2012;20(9):1822-30. Crossref

48. Monllau JC, Poggioli F, Erquicia J, Ramirez E, Pelfort X, Gelber $P$, Torres-Claramunt R. Magnetic Resonance Imaging and Functional Outcomes After a Polyurethane Meniscal Scaffold Implantation: Minimum 5-Year Follow-up. Arthroscopy 2018;34(5):1621-7. Crossref

49. Gelber PE, Isart A, Erquicia JI, Pelfort X, Tey-Pons M, Monllau JC. Partial meniscus substitution with a polyurethane scaffold does not improve outcome after an open-wedge high tibial osteotomy. Knee Surg Sports Traumatol Arthrosc 2015;23(1):334-9. Crossref

50. Moran CJ, Atmaca S, Declercq HA, Cornelissen MJ, Verdonk PC. Cell distribution and regenerative activity following meniscus replacement. Int Orthop 2014;38(9):1937-44. Crossref

51. Verdonk $P$, Beaufils $P$, Bellemans J, Djian $P$, Heinrichs EL, Huysse W, Laprell H, Siebold R, Verdonk R; Actifit Study Group. Successful treatment of painful irreparable partial meniscal defects with a polyurethane scaffold: two-year safety and clinical outcomes. Am J Sports Med 2012;40(4):844-53. Crossref

52. Bulgheroni E, Regazzola G, Mazzola C, Bulgheroni P. Polyurethane scaffold for the treatment of partial meniscal tears. Clinical results with a minimum two-year follow-up. Joints 2013;1(4):161-6. Crossref 
53. Spencer SJ, Saithna A, Carmont MR, Dhillon MS, Thompson $\mathrm{P}$, Spalding T. Meniscal scaffolds: early experience and review of the literature. Knee 2012;19(6):760-5. Crossref

54. Dhollander A, Verdonk P, Verdonk R. Treatment of Painful, Irreparable Partial Meniscal Defects With a Polyurethane Scaffold: Midterm Clinical Outcomes and Survival Analysis. Am J Sports Med 2016;44(10):2615-21. Crossref

55. Bulgheroni E, Grassi A, Campagnolo $M$, Bulgheroni $P$, Mudhigere A, Gobbi A. Comparative Study of Collagen versus Synthetic-Based Meniscal Scaffolds in Treating Meniscal Deficiency in Young Active Population. Cartilage 2016;7(1):29-38. Crossref

56. Houck DA, Kraeutler MJ, Belk JW, McCarty EC, Bravman JT. Similar clinical outcomes following collagen or polyurethane meniscal scaffold implantation: a systematic review. Knee Surg Sports Traumatol Arthrosc 2018. Crossref

57. Shin YS, Lee HN, Sim HB, Kim HJ, Lee DH. Polyurethane meniscal scaffolds lead to better clinical outcomes but worse articular cartilage status and greater absolute meniscal extrusion. Knee Surg Sports Traumatol Arthrosc 2017. Crossref

58. Dangelmajer S, Familiari F, Simonetta R, Kaymakoglu M, Huri G. Meniscal Transplants and Scaffolds: A Systematic Review of the Literature. Knee Surg Relat Res 2017;29(1):310. Crossref

59. Oda S, Otsuki S, Kurokawa Y, Hoshiyama Y, Nakajima $M$, Neo M. A new method for meniscus repair using type I collagen scaffold and infrapatellar fat pad. J Biomater Appl 2015;29(10):1439-48. Crossref

60. Warnock JJ, Fox DB, Stoker AM, Beatty M, Cockrell M, Janicek JC, Cook JL. Culture of equine fibroblast-like synoviocytes on synthetic tissue scaffolds towards meniscal tissue engineering: a preliminary cell-seeding study. Peer J PrePrints 2014;2:e283v1. Crossref

61. Zellner J, Hierl K, Mueller M, Pfeifer C, Berner A, Dienstknecht T, Krutsch W, Geis S, Gehmert S, Kujat R, Dendorfer S, Prantl L, Nerlich M, Angele P. Stem cell-based tissue-engineering for treatment of meniscal tears in the avascular zone. J Biomed Mater Res B Appl Biomater 2013;101(7):1133-42. Crossref

62. Weinand C, Peretti GM, Adams SB Jr, Bonassar LJ, Randolph MA, Gill TJ. An allogenic cell-based implant for meniscal lesions. Am J Sports Med 2006;34(11):1779-89. Crossref
63. Gruchenberg K, Ignatius A, Friemert B, von Lubken F, Skaer N, Gellynck K, Kessler O, Dürselen L. In vivo performance of a novel silk fibroin scaffold for partial meniscal replacement in a sheep model. Knee Surg Sports Traumatol Arthrosc 2015;23(8):2218-29. Crossref

64. Halili AN, Hasirci N, Hasirci V. A multilayer tissue engineered meniscus substitute. J Mater Sci Mater Med 2014;25(4):1195209. Crossref

65. Sarem M, Moztarzadeh F, Mozafari M, Shastri VP. Optimization strategies on the structural modeling of gelatin/ chitosan scaffolds to mimic human meniscus tissue. Mater Sci Eng C Mater Biol Appl 2013;33(8):4777-85. Crossref

66. Esposito AR, Moda M, de Melo Cattani SM, de Santana GM, Barbieri JA, Munhoz MM, Cardoso TP, Barbo MLP, Russo T, D'Amora U, Gloria A, Ambrosio L, de Rezende Duek EA. PLDLA/PCL-T Scaffold for Meniscus Tissue Engineering. Biores Open Access 2013;2(2):138-47. Crossref

67. Freymann U, Endres M, Neumann K, Scholman HJ, Morawietz L, Kaps C. Expanded human meniscus-derived cells in 3-D polymer-hyaluronan scaffolds for meniscus repair. Acta Biomater 2012;8(2):677-85. Crossref

68. Stabile KJ, Odom D, Smith TL, Northam C, Whitlock PW, Smith BP, Van Dyke ME, Ferguson CM. An acellular, allograftderived meniscus scaffold in an ovine model. Arthroscopy 2010;26(7):936-48. Crossref

69. Kon E, Filardo G, Zaffagnini S, Di Martino A, Di Matteo B, Marcheggiani Muccioli GM, Busacca M, Marcacci M. Biodegradable polyurethane meniscal scaffold for isolated partial lesions or as combined procedure for knees with multiple comorbidities: clinical results at 2 years. Knee Surg Sports Traumatol Arthrosc 2014;22(1):128-34. Crossref

70. Stone KR, Steadman JR, Rodkey WG, Li ST. Regeneration of meniscal cartilage with use of a collagen scaffold. Analysis of preliminary data. J Bone Joint Surg Am 1997;79(12):1770-7. Crossref

71. Zaffagnini S, Marcheggiani Muccioli GM, Lopomo N, Bruni D, Giordano G, Ravazzolo G, Molinari M, Marcacci M. Prospective long-term outcomes of the medial collagen meniscus implant versus partial medial meniscectomy: a minimum 10-year follow-up study. Am J Sports Med 2011;39(5):977-85. Crossref 